\title{
Dynamic Energy Consumption and Emission Modelling of Container Terminal based on Multi Agents
}

\author{
Jue Hou
}

China Waterborne Transport Research Institute, Ministry of Transport of the People's Republic of China, Haidian District, Beijing, China

\begin{abstract}
Environmental protection and energy saving pressure press the increasing attention of container terminal operators. In order to comply with the more and more strict environmental regulation, reducing energy consumption and air pollution emissions, meanwhile, optimizing the operation efficiency, which, is an urgent problem to container terminal operator of China. This paper based on the characteristic of Container Terminal Operation System (CTOS), which includes several sections of container product processes, consist of berth allocation problem, truck dispatching problem, yard allocation problem and auxiliary process. Dynamic energy consumption and emissions characteristic of each equipment and process is modelled, this paper presents the architecture of CTOS based on the multi agent system with early-warning model, which is based on multi-class support vector machines (SVM). A simulation on container terminal is built on the JADE platform to support the decision-making of container terminal, which can reduce energy consumption and air pollution emissions, allows the container terminal operator to be more flexible in their decision to meet the Emission Control Area regulation and Green Port Plan of China.
\end{abstract}

\section{Introduction}

In the last more than a decade years, with China's domestic and foreign trade continues to expand, container transport is increasingly valued, environmental protection and energy saving pressure press the increasing attention of government and container terminal operators. China has started the Green Port Plan from 2011, which is total life cycle and closed-loop in operation of port, includes several evaluation indicators, to evaluate operation management level of environment and energy efficiency of port. Four years later, China has established the three Emission Control Areas (ECAs) in 2015, Three ECAs include the Pearl River Delta, the Yangtze River Delta, and in the Bohai Sea. They have been created to reduce the levels of ship-generated air pollution and mainly focus on the sulphur content of fuels.

In order to improve energy efficiency and reduce emission, and get dynamic information in advance, this paper based on the characteristic of Container Terminal Operation System (CTOS), which includes several sections of container product processes, and consist of berth allocation problem, truck dispatching problem, yard allocation problem and auxiliary process. Dynamic energy consumption and emissions characteristic of each equipment and process is modelled, this paper presents the architecture of CTOS based on the multi agent system with early-warning model, which is based on multi-class Support Vector Machines (SVM) algorithm. A simulation on container terminal is built on the JADE platform to support the decision-making of container terminal, which can reduce energy consumption and air pollution emissions, and allows the container terminal operator to be more flexible in their decision to meet the environmental protection regulation and green port plan of China.

\section{Modelling}

In order to reflect the energy consumption and emission of container terminal comprehensively, this paper presents a model, considering the dynamic energy consumption and mission of process of container terminal, which based on Container Terminal Operation System (CTOS) with early warning model.

\subsection{Container Terminal Operation System}

CTOS is a complex discrete dynamic system which reflect a series of operation process in container terminal. The energy consumption and emission problem based on CTOS is mainly for four problems in this study, when container ships arrive at terminal through anchorage, which berth should be allocated to the mooring ship, called berth allocation problem (BAP) [1 2], includes ship, quay crane and shore power system (SPS). Then, ships are handled by quay cranes, and containers of ships are transhipped by trucks between quay and yard, which called the truck allocation problem (TDP) [3 6]. In yard stack of container terminal, yard crane and truck need cooperate with each other, to transport and storage 
container, called the yard allocation problem (YAP) [7], as shown in Figure 1. The auxiliary process of operation includes lighting, refrigeration and heating, cleaning and so on.

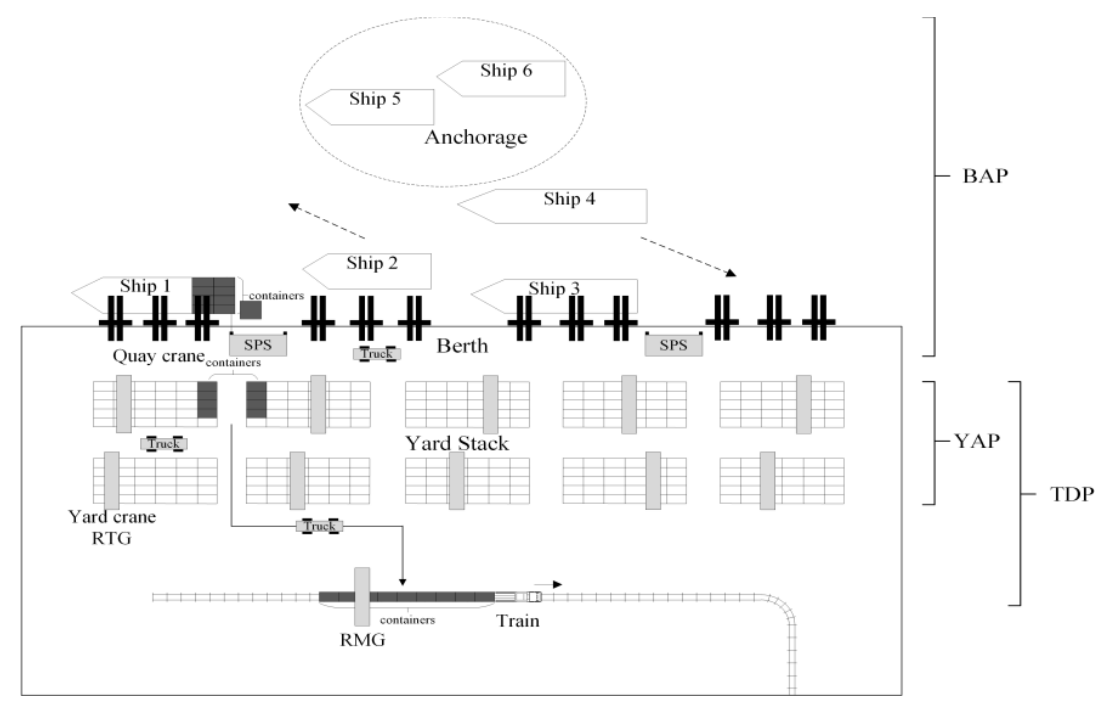

Figure 1. A typical container terminal and its operation process.

The subsystems structure of CTOS in this paper as shown in Figure 2, including location subsystem and equipment subsystem. Each subsystem represents the transhipment of location and handle equipment of container flow in CTOS, which could reflect dynamic characteristic of energy consumption and emission. CTOS will be modelled in the next section.

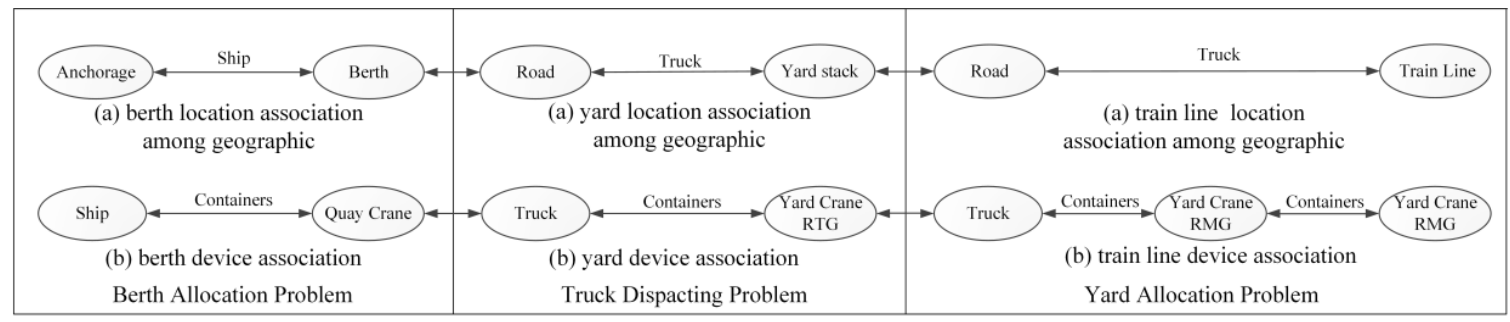

Figure 2. Flowchart of Container Terminal Operation System

\subsection{Dynamic Energy Consumption and Emission Model}

Consider the multi variables of energy consumption (electric, diesel, LNG, etc.). The model as shown in Figure 3. Based on the dynamic energy consumption

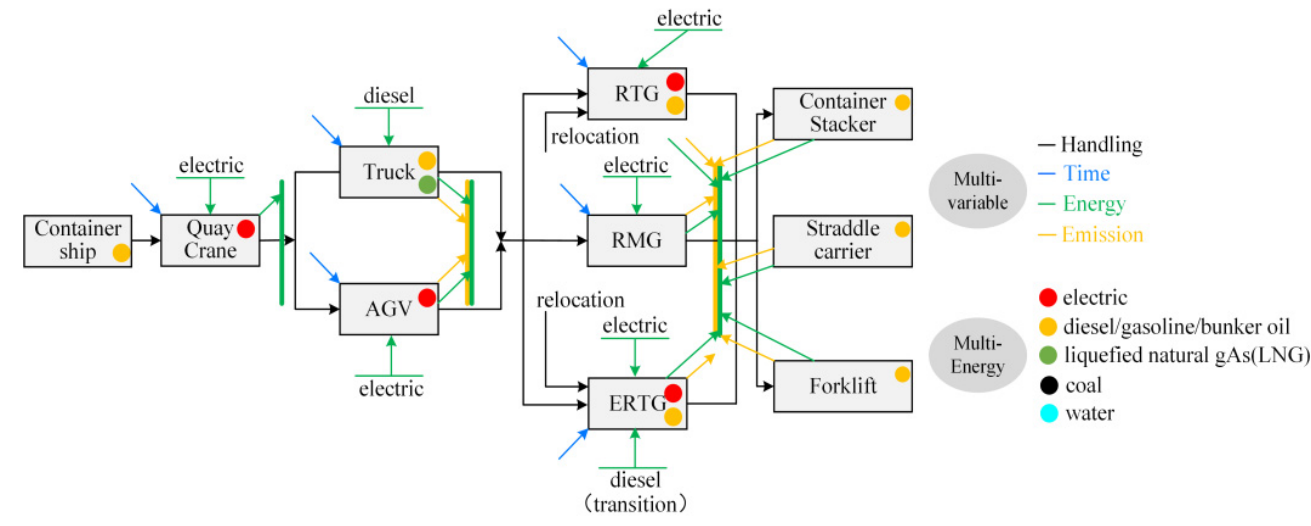

Figure 3. Multi variable and energy of container terminal.

and emission, container operator analysis the process which is high energy consumption and emission, and take actions to reduce. 


\subsection{Early-warning model}

To evaluate the level of terminals in energy efficiency and emission, the early warning model is built, which could help the container operator to obtain the information about energy consumption and emission. An early warning model dealing with terminal energy consumption and pollutant emission is built based on three levels, including normal, early warning and warning, Multi-Class Support Vector Machine (MSVM) is used to solve the model.

The evaluation of energy consumption and emission of container terminal can be regarded as a machine learning problem which based on empirical data, and the solution steps as follows:

- Step 1 selects training data set

Collect energy consumption and emission training data set.

- Step 2 identifies training models

Expert experience is used to assign weights and determine training data set.

- Step 3 selects the kernel function

The training data is analysed and judged to be linear separable or non-separable, and different kernel functions are designed to solve the model.

- Step 4 forecast early warning level

Training data and cross validation and scoring the three SVM models, warning levels, classification hyperplane and support vector are obtained.

- Step 5 accuracy verification

Model accuracy verification.

\subsection{Approach of early-warning model}

Support Vector Machine (SVM) is based on statistical learning theory which is a kind of machine learning method, considering the training error and the generalization ability, to search for the best compromise solution. SVM is originally proposed for two classification problem, but it is often proposed for multi classification problem. If the input space of the training set is linearly separable, there is a hyperplane as:

$$
y_{i}\left(\mathbf{w}^{T} x_{i}+b\right) \geq \pm 1 \quad i=1,2, \mathrm{~L}, n .
$$

The interval between the two classes can be calculated as $2 /\|\mathbf{w}\|$ the minimum value of the interval between the two classes:

$$
\left\{\begin{array}{l}
\min _{w, b} \frac{1}{2} \mathbf{w}^{T} \mathbf{w} \\
\text { s.t. } y_{i}\left(\mathbf{w}^{T} x_{i}+b\right) \geq 1 \quad i=1,2, \cdots, n .
\end{array}\right.
$$

Where the $\mathbf{w}$ is the direction vector of the hyperplane, $b$ is the position offset of the classification hyperplane, $n$ is the number of support vectors, then the optimal hyperplane $f$ is determined, and the decision function is $s$. For a test sample $x$, if $s=1$, then the $x$ belongs to the positive class, otherwise $x$ belongs to the negative class, so as to achieve the classification of samples.

Using the Lagrange method, the Eq. (2) can be transformed into two programming problems:

$$
\left\{\begin{array}{l}
\min _{w, b} \max _{\alpha} L(\mathbf{w}, b, \alpha)=\frac{1}{2} \mathbf{w}^{T} \mathbf{w}-\sum_{i=1}^{n}\left[y_{i}\left(\mathbf{w}^{T} x_{i}+b\right)-1\right] \\
\text { s.t. } \sum_{i=1}^{n} y_{i} \alpha_{i}=0 \quad \alpha_{i} \geq 0, i=1,2, \cdots, n .
\end{array}\right.
$$

If the input space of the training set is linearly nonseparable, a relaxation term is added to the constraint condition Eq. (2), and then the two optimization problem is transformed into the following:

$$
\left\{\begin{array}{l}
\min _{w, b_{j}, \xi} \frac{1}{2} \mathbf{w}^{T} \cdot \mathbf{w}+C \sum_{i=1}^{n} \xi_{i} \\
\text { s.t. } y_{i}\left(\mathbf{w}^{T} x_{i}+b\right) \geq 1-\xi_{i}, \quad \xi_{i} \geq 0 \quad i=1,2, \mathrm{~L}, n .
\end{array}\right.
$$

Where $C$ is a constant, used to control the trade-off between the maximum interval and the minimum training error, called the penalty factor, and the two programming problem can be transformed into the following dual forms:

$$
\left\{\begin{array}{l}
\max _{\alpha} L(\alpha)=\sum_{i=1}^{n} \alpha_{i}-\frac{1}{2} \sum_{i=1}^{n} \sum_{j=1}^{n} y_{i} y_{i} \alpha_{i} \alpha_{j} K\left(x_{i}, x_{j}\right) \\
\text { s.t. } \sum_{i=1}^{n} y_{i} \alpha_{i}=0 \quad \alpha_{i} \geq 0, i=1,2, \mathrm{~L}, n .
\end{array}\right.
$$

In order to solve the problem of multiple classifiers, this paper presents the optimal decision function as [8 9]:

$$
f_{s t}(x)=\mathbf{w}_{s t} \cdot \phi(x)+b_{s t}=\sum_{i=s v} \alpha_{i}^{s t} y_{i} K\left(x_{i}, x\right)+b_{s t}
$$

\section{Multi Agents System using for Modelling}

\subsection{Multi Agents System}

CTOS could solve the conflicts between operation efficiency, energy consumption and emission in reasonable strategy of container terminal. Multi-Agents System (MAS) can solve some complex task and target.

Simulation is not so strongly which is limited by the size and complexity of the CTOS and can usually cover all required subsystems in a single model, respecting their mutual relations as well [10 12]. Multi-Agents System (MAS) is a complex system that consists of agents which are the characteristics of autonomy, cooperation, and sociality [13 16], and it can reflect container terminal operating process. MAS is typical discrete, distribute and dynamic system, could meet functional requirements of the CTOS. This paper study the CTOS based on MAS, using the below characteristics: the autonomy, when the CTOS sends request, the agent do not accept request until the task is finished. The cooperation: when the container transport or operation task could not be completed by single agent, the task by coordination and negotiation with other agents. The sociality: the agents bring about communication, collaboration, coordination and negotiation with the others. This study has a sequence 
of discrete time steps ( $1 \mathrm{sec}$ ), at each time step, the agent receives a state from the environment. At the next time step, as a consequence of its action, the agent receives a new task and moves to a new state.

This paper with the CTOS consists of two subsystems, the location subsystem and equipment subsystem. Location subsystem is composed of anchorage agents, berth agents, stack yard agents, road agents and train loading and unloading line agents.

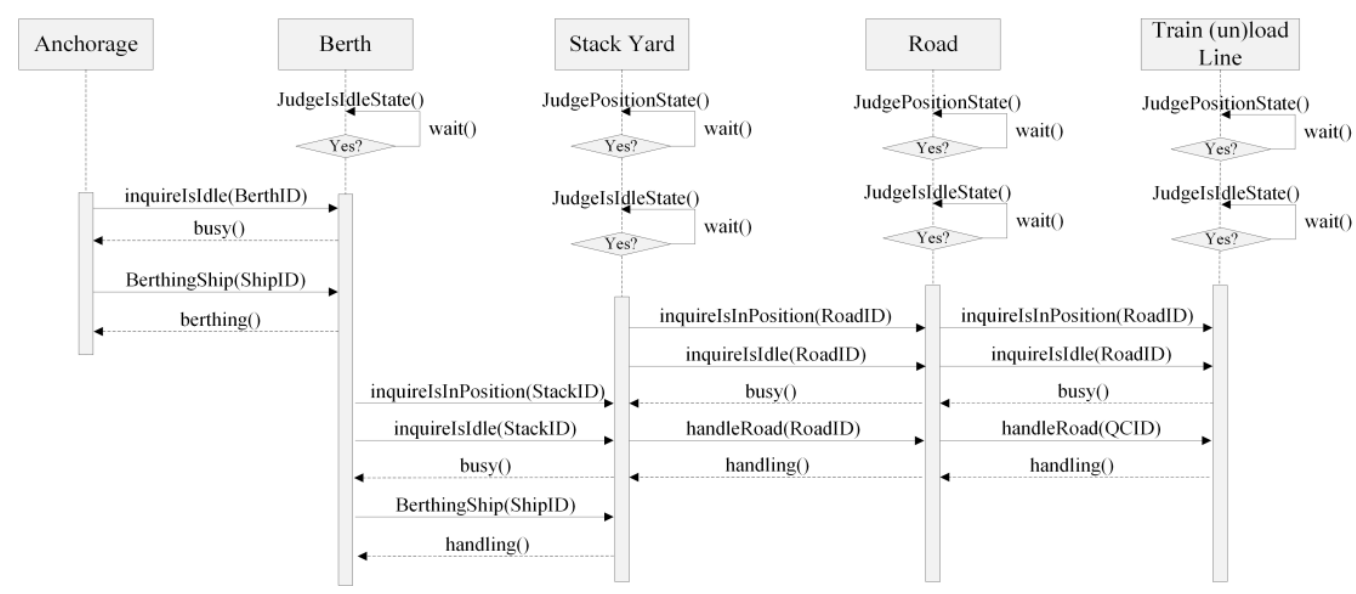

Figure 4. Location subsystem interaction sequence diagram of container terminal operation system

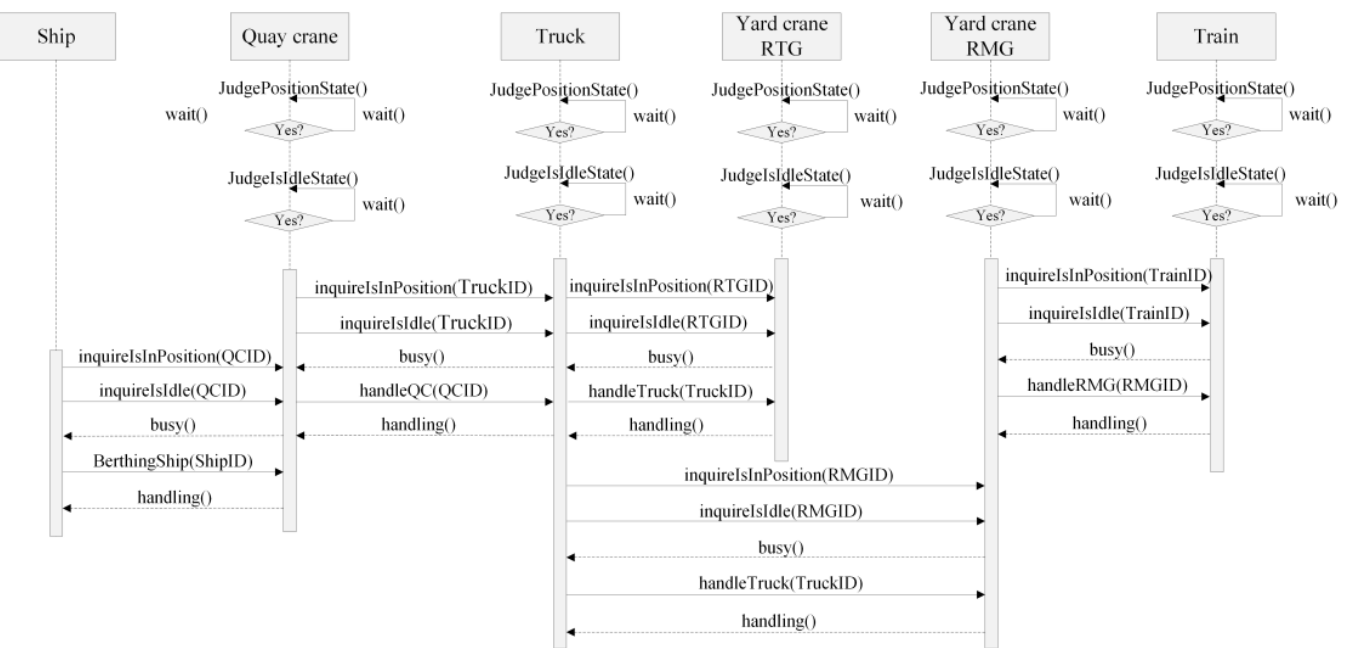

Figure 5. Equipment subsystem interaction sequence diagram of container terminal operation system

\subsection{Platform}

In this paper, all the container terminal agents are developed over the Java Agent Development framework (JADE) platform, which is a programming and simulation environment based on Java that matches with Unified Modelling Language (UML), and conforms to the Foundation for Intelligent Physical Agents (FIPA) specifications. MAS based on JADE platform allows the user to combine different techniques and approaches such as differential equations and discrete events with container terminal operation. This paper build a CTOS simulation model based on JADE platform, the framework of which is divided into four layers.

The first layer is Java platform, which ensure the flexibility and portability of the MAS system. The second
They are responsible for handling locations of the CTOS. The interaction sequence between these location agents as shown in Figure 4. Equipment subsystem is composed of ship agents, quay crane agents, truck agents, yard crane agents and train agents. They are responsible for handling operation of the CTOS. The flow of containers is bi-direction, the import and export, the interaction sequence of import container between these equipment agents as shown in Figure 5.

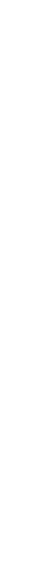




\section{Empirical study}

This study performs a simulation research on a container terminal in Yangtze ECA of China, which has a throughput capacity of 1,000,000 TEU per year. In order to evaluate possible impacts both on environmental and energy consumption. The container terminal design parameters as in Table 1.

Due to the transport distance of container is variable, which is calculated by distance divide to truck and train move speed, as shown in Table 2 .
Table 1. The container terminal parameters

\begin{tabular}{|c|c|c|}
\hline Agent & Item & Parameter \\
\hline \multirow{4}{*}{ Quay } & shoreline & 1300 meter \\
\cline { 2 - 3 } & berth & 4 \\
\cline { 2 - 3 } & shore power & 2 \\
\hline \multirow{5}{*}{ Stack Yard } & yard area & 30 kilo square \\
\cline { 2 - 3 } & stacks & 8 \\
\cline { 2 - 3 } & stack yard length & 100 meter \\
\cline { 2 - 3 } & stack yard width & 30 meter \\
\cline { 2 - 3 } & stack yard capacity & 85 TEU \\
\cline { 2 - 3 } & each length & $100 \sim 168$ meter \\
\cline { 2 - 3 } Road & each width & $61.2 \sim 83.5$ meter \\
\hline & north-south road & 6 \\
\cline { 2 - 3 } & east-west road & 3 \\
\cline { 2 - 3 } & road width & 22 meter \\
\hline
\end{tabular}

Table 2. The equipment data in container terminal

\begin{tabular}{|c|c|c|c|c|c|c|}
\hline Agent & $\begin{array}{c}\text { Power } \\
(k W)\end{array}$ & $\begin{array}{c}\text { Size } \\
\mathrm{L} \times \mathrm{W} \times \mathrm{H} \\
(\text { meter })\end{array}$ & $\begin{array}{c}\text { Operation Time } \\
(\text { secs/TEU })\end{array}$ & $\begin{array}{c}\text { Move Speed } \\
(\text { meters } / \text { sec })\end{array}$ & Number & Energy \\
\hline Quay Crane & 900 & $65 \times 30 \times 10$ & 50 & 0.40 & 12 & electric \\
\hline RTG & 450 & $30 \times 31 \times 19$ & 30 & 0.30 & 5 & diesel \\
\hline ERTG & 480 & $30 \times 31 \times 19$ & 35 & 0.25 & 28 & electric \\
\hline RMG & 450 & $30 \times 31 \times 19$ & 35 & 0.23 & 2 & diesel \\
\hline Truck & 100 & $12.5 \times 2 \times 3$ & variable & 1.10 & 50 & diesel \\
\hline Empty container stacker & 100 & $12.5 \times 2 \times 3$ & 50 & 1.50 & 5 & diesel \\
\hline Straddle carrier & 100 & $12.5 \times 2 \times 3$ & 100 & 0.40 & 1 & diesel \\
\hline Forklift & 100 & $12.5 \times 2 \times 3$ & 100 & 1.00 & 4 & diesel \\
\hline Train(locomotive) & 2500 & $21 \times 3 \times 4$ & variable & variable & 2 & diesel \\
\hline
\end{tabular}

According to the ECA regulation, when the ship without on-board shore power system installing in berthing period, they need to take the $0.5 \%$ sulphur MGO fuel, and $0.1 \%$ sulphur diesel fuel for truck.

In exprientmat study, design two days to contrast. The throughput of container terminal is 12245 TEU in day 1 , without optimization strategy, the energy consumption and emission as shown in Table 3.

Table 3. The energy consumption and emission of container terminal in day 1 .

\begin{tabular}{|c|c|l|c|}
\hline Process & No. & \multicolumn{1}{|c|}{ Index } & Value \\
\hline \multirow{4}{*}{$\begin{array}{c}\text { Energy } \\
\text { and } \\
\text { Emission }\end{array}$} & 1 & Diesel/ kg & 1115.25 \\
\cline { 2 - 4 } & 2 & Power/ $\mathrm{kWh}$ & 5688.94 \\
\cline { 2 - 4 } & 3 & $\mathrm{CO}_{2} / \mathrm{kg}$ & 3714.187 \\
\cline { 2 - 4 } & 4 & $\mathrm{SOx} / \mathrm{kg}$ & 2398.52 \\
\cline { 2 - 4 } & 5 & $\mathrm{NO} / \mathrm{kg}$ & 595.93 \\
\hline \multirow{5}{*}{ Equipment } & 6 & $\mathrm{PM} / \mathrm{kg}$ & 155.45 \\
\cline { 2 - 4 } & 7 & $\mathrm{QC} \mathrm{kWh} / \mathrm{TEU}$ & 0.221 \\
\cline { 2 - 4 } & 8 & Truck $\mathrm{kg} / \mathrm{TEU}$ & 0.045 \\
\cline { 2 - 4 } & 9 & ERTG $\mathrm{kWh} / \mathrm{TEU}$ & 0.046 \\
\cline { 2 - 4 } & 10 & $\mathrm{RTG} \mathrm{kg} / \mathrm{TEU}$ & 0.059 \\
\cline { 2 - 4 } & 11 & RMG $\mathrm{kg} / \mathrm{TEU}$ & 0.054 \\
\cline { 2 - 4 } & 13 & Empty stacker $\mathrm{kg} / \mathrm{TEU}$ & 0.078 \\
\cline { 2 - 4 } & 14 & Ftraddle carrier $\mathrm{kg} / \mathrm{TEU}$ & 0.069 \\
\hline
\end{tabular}

Figure 6 shows result of a early warning model in day 1 by using MAS simulation model of the CTOS, there are nine warning hour points in operation of container terminal, the Aux reprensents the auxiliary operation.

\begin{tabular}{|c|c|}
\hline Day 1/Hour & \begin{tabular}{|l|l|l|l|l|l|l|l|l|l|l|l|}
01 & 02 & 03 & 04 & 05 & 06 & 07 & 08 & 09 & 10 & 11 & 12 \\
\end{tabular} \\
\hline BAP & 000000000000 \\
\hline YAP & O \\
\hline TDP & 000 \\
\hline Aux & $0.000000 \mathrm{OC}$ \\
\hline Day 1/Hour & \begin{tabular}{|l|l|l|l|l|l|l|l|l|l|l|l|}
13 & 14 & 15 & 16 & 17 & 18 & 19 & 20 & 21 & 22 & 23 & 24 \\
\end{tabular} \\
\hline BAP & $000000000 \mathrm{C}$ \\
\hline YAP & $\mathrm{OOOC}$ \\
\hline TDP & 0000000 \\
\hline Aux & 0.0000000 .000 \\
\hline
\end{tabular}

Figure 6. Diagram of early warning model in day 1.

As contrast, container terminal operator adopts optimization strategy to improve efficiency, throughput of container terminal is 11305 TEU in day 2, energy consumption and emission as shown in Table 4.

Table 4. The energy consumption and emission of container terminal in day 2 . 


\begin{tabular}{|c|c|l|c|}
\hline Process & No. & \multicolumn{1}{|c|}{ Index } & Value \\
\hline \multirow{4}{*}{$\begin{array}{c}\text { Energy } \\
\text { and } \\
\text { Emission }\end{array}$} & 1 & Diesel/ $\mathrm{kg}$ & 984.54 \\
\cline { 2 - 4 } & 2 & Power/ $\mathrm{kWh}$ & 5356.90 \\
\cline { 2 - 4 } & 3 & $\mathrm{CO}_{2} / \mathrm{kg}$ & 3111.28 \\
\cline { 2 - 4 } & 4 & $\mathrm{SOx} / \mathrm{kg}$ & 2198.52 \\
\cline { 2 - 4 } & 5 & $\mathrm{NOx} / \mathrm{kg}$ & 595.93 \\
\cline { 2 - 4 } & 6 & $\mathrm{PM} / \mathrm{kg}$ & 155.45 \\
\hline \multirow{5}{*}{ Equipment } & 7 & $\mathrm{QC} \mathrm{kWh} / \mathrm{TEU}$ & 0.201 \\
\cline { 2 - 4 } & 8 & Truck $\mathrm{kg} / \mathrm{TEU}$ & 0.041 \\
\cline { 2 - 4 } & 9 & ERTG $\mathrm{kWh} / \mathrm{TEU}$ & 0.040 \\
\cline { 2 - 4 } & 10 & RTG $\mathrm{kg} / \mathrm{TEU}$ & 0.056 \\
\cline { 2 - 4 } & 11 & RMG $\mathrm{kg} / \mathrm{TEU}$ & 0.050 \\
\cline { 2 - 4 } & 12 & Empty stacker $\mathrm{kg} / \mathrm{TEU}$ & 0.063 \\
\cline { 2 - 4 } & 13 & Straddle carrier kg/TEU & 0.066 \\
\cline { 2 - 4 } & 14 & Forklift kg/TEU & 0.073 \\
\hline
\end{tabular}

After the early warning model, contianer terminal operator adopts optimization strategy to improve efficiency, reduce energy consumption and emissions, Figure 7 shows result of a early warning model in day 2 by using MAS simulation model of the CTOS, only three warning hour points in operation of container terminal.

\begin{tabular}{|c|c|}
\hline Day 2/Hour & \begin{tabular}{|l|l|l|l|l|l|l|l|l|l|l|l|}
01 & 02 & 03 & 04 & 05 & 06 & 07 & 08 & 09 & 10 & 11 & 12 \\
\end{tabular} \\
\hline BAP & 000000000000 \\
\hline YAP & 000000000000 \\
\hline TDP & 0 \\
\hline Aux & 0.000000000 \\
\hline Day 2/Hour & \begin{tabular}{|l|l|l|l|l|l|l|l|l|l|l|l|}
13 & 14 & 15 & 16 & 17 & 18 & 19 & 20 & 21 & 22 & 23 & 24 \\
\end{tabular} \\
\hline BAP & 000000000000 \\
\hline YAP & \\
\hline TDP & \\
\hline Aux & $000000000 \mathrm{C}$ \\
\hline
\end{tabular}

Figure 7. Diagram of early warning model in day 2.

Empirical study shows the dynamic energy consumption and emission model based on CTOS using MAS with early-warning model that can improve efficiency, reduce energy consumption and emissions.

\section{Conclusions}

In order to reflect the energy consumption and emission of container terminal comprehensively, this paper presents a model, considering the dynamic energy consumption and mission of process of container terminal, which based on Container Terminal Operation System (CTOS) with early warning model. This paper based on the characteristic of CTOS, dynamic energy consumption and emissions characteristic of each equipment and process is modelled, this paper presents the architecture of CTOS based on MAS with early-warning model with M-SVM. A simulation on container terminal is built on the JADE platform to support the decision-making of container terminal, which can reduce energy consumption and air pollution emissions, allows the container terminal operator to be more flexible in their decision to meet the Green Port Plan of China.

\section{Acknowledgements}

This research was partly supported carried out with financial support from the Conserve Energy and Reduce Emissions Grant (CEREG) No.2014-JNJP-008-037 and No.2015-JNJP-010-056, from the Ministry of Transport of the People's Republic of China.

\section{References}

1. Imai, A., Sun, X., Nishimura, E., \& Papadimitriou, S. (2005). Berth allocation in a container port: using a continuous location space approach. Transportation Research Part B Methodological, 39(3), 199-221.

2. Golias, M.M., Saharidis, G.K., Boile, M., Theofanis, S., Ierapetritou, M.G., 2009. The berth allocation problem: optimizing vessel arrival time. Marit. Econom.Logist. 11 (4), 358-377.

3. Yan S, Lai W, Chen M. Production scheduling and truck dispatching of ready mixed concrete $[\mathrm{J}]$. Transportation Research Part E, 2008, 44(1):164-179.

4. Liao C H, Tseng P H, Lu C S. Comparing carbon dioxide emissions of trucking and intermodal container transport in Taiwan[J]. Transportation Research Part D, 2009, 14(7):493-496.

5. Yan S, Lai W, Chen M. Production scheduling and truck dispatching of ready mixed concrete[J]. Transportation Research Part E, 2008, 44(1):164-179.

6. Liao C H, Tseng P H, Lu C S. Comparing carbon dioxide emissions of trucking and intermodal container transport in Taiwan[J]. Transportation Research Part D, 2009, 14(7):493-496.

7. Ya X, Qiushuang C, Xiongwen Q. A robust integrated approach to yard space allocation and crane scheduling in container terminals $[\mathrm{C}] / /$ International Conference on Service Systems and Service Management. IEEE Xplore, 2010:1-6.

8. Li B, Wang Q W, HU J L. Multi-SVM classifier system with piecewise interpolation[J]. IEEJTrans on Electrical and Electronic Engineering, 2013, 8(2):132-138.

9. Li Boyang, Wang Qiangwei, Hu Jinglu. Multi-SVM classifier system with piecewise interpolation[J]. IEEJ Trans on Electrical and Electronic Engineering, 2013, 8( 2) : 132-138.

10. Sun Z, Lee L H, Chew E P, et al. MicroPort: A general simulation platform for seaport container terminals $[\mathrm{J}]$. Advanced Engineering Informatics, 2012, 26(1):80-89.

11. Chhetri P, Jayatilleke G B, Gekara V O, et al. Container terminal operations simulator (CTOS) Simulating the impact of extreme weather events on port operation $[\mathrm{J}]$. European Journal of Transport \& Infrastructure Research, 2016.

12. Kocifaj M, Adamko N. Modelling of container terminals using two-layer agent architecture[C]// IEEE, International Symposium on Applied Machine Intelligence and Informatics. IEEE, 2014:251-256 